\title{
JOSÉ BONIFÁCIO, O POLÍTICO $\left({ }^{\star}\right)$.
}

Em 1819, ao retornar a São Paulo, donde partira jovem havia trinta e seis anos, José Bonifácio era, se não um homem em busca de repouso, pelo menos alguém que, nesse intervalo entre a vida e a morte, esperava dar o arremate a afarosa existência de cientista. Nada de política... nada de negócios de Estado... nada de cargos eletivos. E talvez julgasse ser um bem, dado o temperamento "fogoso, violento, apaixonado", que lhe imputou Latino Coelho, e que não era apenas dêle, mas dos Andradas, todos por certo ainda lembrados do que custara ao irmão Antônio Carlos a sua participação na revolução de 1817. José Bonifácio estava livre dêsses perigos. Tranqüilamente, iria cuidar, como sempre, da mineralogia, da metalurgia, da filosofia, da literatura. Ele próprio, aliás, muito lúcido, deixou esta confissão: "Nascido com um temperamento fervido, o meu primeiro movimento é uma doidice completa e atrevida, que tomo por uma nobre intrepidez". Sangue na guelra, diz-se em linguagem popular. Mas, que importava essa impulsividade a quem, alheio ao bulício da política, ia, como sempre, cuidar dos seus livros e das suas leituras?

Como vêdes, portanto, ao ingressar, em junho de 1821, na Junta Governativa de São Paulo, José Bonifácio, embora outoniço, era neófito na vida política, para a qual - esta é a verdade - fôra arrebatado pelos méritos invulgares, que faziam dêle uma das primeiras cabeças do país. Maria Graham, que tão bem observou muitas das nossas coisas, escreveria a propósito da ilustre família, que girava em tôrno do velho Andrada: "todos os sobrinhos e outros parentes que ali encôntro revelam-se superiores, em educação e conhecimentos à maior parte das pessoas que vejo. Mas é o próprio José Bonifácio que me desperta maior interêsse. E' um homem pequeno, de rosto magro e pálido. Suas maneiras e sua conversa impressionam logo o interlocutor com a idéia daquela

(*). - Conferência pronunciada em Santos a 12 de maio de 1963 (Nota da Ređação). 
atividade mental incansável." $\mathrm{E}$, depois de se referir à sua coleção de química e de mineração "particularmente extensa e rica em autores suecos e alemães", acrescenta: "Mas seu encanto é a literatura clássica. Ele próprio é poeta, e não de ordem inferior."

$\mathrm{E}$ era êsse homem, tão voltado para as calmas atividades da ciência e das belas letras, que, em breve, seria tragado pela mais absorvente, vigorosa, e tumultuosa ação política. Em cinco anos êle se tornaria o Patriarca da Independência, e o Exilado de Pedro I. Grande e surpreendente destino. Mas, por que caminhos terá êle realizado essa trajetória ao mesmo tempo extraordinária e dolorosa?

$\mathrm{Na}$ realidade, embora fôsse um entusiasta, qualidade que Mareschal, num dos seus ofícios para a Côrte da Austria, considerava "pouco própria para um estadista"; e Arouche dissesse dêle que não sabia "o que é política nem como se vive com povos", faltando-lhe prudência, virtude que, de referência aos Andradas, afirmava ser "desconhecida naquela família", na realidade José Bonifácio possuia um conjunto de virtudes, ou melhor, uma personalidade que fêz dêle, na ocasião, o homem do destino. Possuia aquilo que Maquiavel chamou de "virtú". Do seu renome histórico, da sua glória, nada é fruto do acaso. O seu pedestal foi êle que o construiu. A inteligência extraordinàriamente lúcida, a cultura invulgar, a paixão pelo jôgo perigoso e, também, convém acentuar, a fôrça e a firmeza do caráter foram qualidades essenciais à tarefa que lhe coube, e que realizou maravilhosamente, conduzindo os acontecimentos com uma segurança, uma sagacidade, uma oportunidade, que desmentem inteiramente aquêle conceito que pretende diminuí-lo como político. Pelo menos no lance da Independência - e isso é o que importa - êle foi extraordinário. Previu, preparou,.orientou, e conduziu à vitória final, e magnífica. Que mais se pode querer, ou exigir de um político?

Certamente, e talvez pela consciência da própria estatura, José Bonifácio não era um acomodado, um homem de palha. Longe disso, tinha a alma do lutador, e enfrentava, combatia, agredia os que se interceptavam no seu caminho. Ou melhor: os que embaraçavam as suas idéias. Daí os inimigos que teve, e até que ainda tem, e que jamais suportarão a claridade da glória do inolvidável santista. Não se disse, inclusive, que "era oposto à Independência?" A verdade é que mesmo se admitindo já existir um movimento emancipador quando viajou de São Paulo para o Rio de Janeiro, a fim de se tor- 
nar o primeiro brasileiro a ocupar um lugar de ministro, a verdade é que com a sua presença o ministério ganhou outra firmeza, tomou rumos, e se preparou para ser, como devia, o seguro coordenador das gestões, das providênciàs, dos atos que deviam preceder e suceder a proclamação da Independência. Esta deixa de ser um movimento emocional, que conhece o seu objetivo, mas ignora os seus caminhos, para se transformar em alguma coisa organizada, e orientada, cujos passos sabem para onde vão.

Varnhagen, que está longe de ser autor simpático a José Bonifácio, diz com a segurança da sua autoridade: "A entrada, principalmente de José Bonifácio no Ministério veio dar-lhe mais unidade, o que foi de grande conseqüência para a marcha que seguiram os negócios. O seu grande saber, o seu gênio intrépido, o seu caráter pertinaz, que quase chegava a raiar em defeito contribuiram a fixar a volubilidade do príncipe." Opinião inteiramente esposada por Mareschal: "Esse Ministério, escreveu o ministro austríaco, tem unidade e o Sr. Andrada que o formou parece haver conseguido colegas que trabalhando no mesmo rumo nos seus departamentos não buscarão embaraçar sua trajetória por intrigas secretas: inconveniente que em parte causou a queda do Conde dos Arcos."

Ao assumir o Ministério do Reino e dos Estrangeiros - que não fêz sem relutância - que idéias trazia José Bonifácio sôbre as relações entre Brasil e Portugal? Não se pense que eram as da Independência. Verdadeiro ou principal autor de dois importantes documentos do govêrno de São Paulo, as Lembranças e Apontamentos enviados aos deputados paulistas às Côrtes de Lisboa, e a carta de 24 de dezembro ao príncipe regente, por êles podemos conhecer o pensamento do nôvo ministro. No primeiro dêles, além de expressamente reafirmado o propósito de ser mantido o sistema vigente do Reino Unido, pleiteava-se o estabelecimento, no Brasil, de um govêrno geral executivo, que, na realidade seria o eixo da nossa unidade, objetivo constante e primacial de José Bonifácio. Na carta, já sob o impacto dos atos das Côrtes de julho a outubro, e que, entre outras coisas, determinavam a partida do Príncipe, a extinção do Tribunal da Chancelaria, o do Tesouro, e a Junta do Comércio, além da nomeação para cada Província de um Governador das Armas, delegado de Lisboa; $\epsilon$ independente da Junta local, na carta não varia a linguagem de José Bonifácio. Embora afirmasse que "logo ferveu em nossos corações uma nobre indignação", punha tôda a ên- 
fase na permanência do Príncipe, a fim de combater e vencer as decisões portuguêsas destinadas a "desunir-nos, enfraquecer-nos, e até deixar-nos em mísera orfandade". Nenhuma referência, porém, à Independência. E ninguém se surpreenda ou estranhe tal omissão. A Representação do Senado da Câmara do Rio de Janeiro, em 23 de maio de 1822, maio de 1822, repito, que tinha como primeiro signatário José Clemente Pereira, parceiro de Ledo e do Cônego Januário, apontados pelos desafetos de José Bonifácio como os arautos da Independência, e pedia a convocação de uma Assembléia Geral das Províncias, também silencia sôbre a Independência. Ou, o que é ainda mais expressivo, aponta a convocação dessa Assembléia como necessária à sobrevivência do Reino Unido. "Eia pois, Senhor, - diz a Representação - o perigo da desunião está iminente, as circunstâncias urgem, a salvação da Pátria impera... Convoque Vossa Alteza Real já nesta Côrte uma Assembléia Geral das Províncias do Brasil e a união com Portugal será mantida...

Aliás, muito cêdo se convenceu José Bonifácio de que soara a hora da Independência. Já em maio, quando José Clemente lutava para salvar "a união com Portugal", já em maio c nosso Patriarca preparava o grande ato da Independência. Por êsse tempo chegara ao Rio o relatório apresentado às Côrtes pela comissão dos negócios políticos do Brasil, e, dadas as concessões feitas, fôra grande a satisfação com que a cidade acolhera a notícia. O próprio Antônio Carlos, um dos signatários do documento, atribuia-lhe grandes vantagens para o Brasil; e o certo é que o Rio engalanou-se, e iluminou-se para celebrar a boa nova. Houve uma exceção: José Bonifácio, cuja residência, no Largo do Rocio, permaneceu apagada. Por que? Fôsse êle ainda partidário do Reino Unido, e que melhor oportunidade do que essa para se reajustarem os ponteiros com Portugal?

$\mathrm{Na}$ realidade, êle já tomara outro caminho - o da Independência. Maler, então encarregado de negócios da França, no Brasil, naturalmente com a sua experiência, digamos o bom faro de diplomata, não teve dúvida sôbre isso, e tratou de aprofundar as indagações a respeito. Nestas condições não teve surprêsa quando o ministro da Marinha, cheio de mágoa, confirmou-lhe que José Bonifácio apressava a separação das duas nações. $\mathrm{E}$ Mareschal, que ouvira então o ministro do Reino declarar, perante mais de vinte pessoas, ser necessária "a grande Aliança ou Federação Americana", informou, a pro- 
pósito da campanha dos jornais e dos boletins contra o mencionado relatório, "parecer que o Ministério havia, êle próprio, encorajado essas opinióes".

Evidente, portanto, que êle já traçara o seu rumo: sabia para onde ia. O que não faria era seguir o caminho dos outros. A sua bússola era a dêle, e daí os ataques, as acusações, as negações de que foi alvo. Senhor de forte personalidade, não o intimidavam as críticas ou ameaças, inclusive as do ativo grupo da maçonaria. Com a língua sôlta, apaixonado êle $o$ enfrentava, combatia, e quase sempre venceu.

Restaria saber se escolheu o caminho certo. E' o que vamos ver.

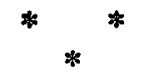

Num delicioso ensaio sôbre O Político, Louis Barthou inseriu êste conceito exato: "A ação é a pedra de toque pela qual se reconhece o verdadeiro político." O político, isto é, o homem votado à causa pública, em cujo serviço pode enganarse; mas, que, ao contrário do que ocorre com o politiqueiro, fiel aos seus interêsses pessoais, jamais engana.

Pois bem, José Bonifácio que podemos dizer não haver antes exercido atividade na vida pública, revelou-se, ao assumir o ministério, senhor de raros e extraordinários dotes de político.

Inicialmente, compreendeu quanto seria útil, se não imprescindível, a participação ativa de $\mathrm{D}$. Pedro nos episódios que se iriam seguir. Por isso, ao contrário do que fizera o Conde dos Arcos, que, segundo uma observação de Mareschal, adormecia as faculdades do Príncipe, a fim de governàr livremente, José Bonifácio o colocou à frente e encorajou-lhe a atividade. Mais do que isso - mal grado as semelhanças de temperamento que deviam tornar mais difícil o bom entendimento, tratou de captar as estima e a confiança de D. Pedro. Haverá algo mais importante para o bom êxito de um ministro? E não foi pela lisonja que alcançou tal desideratum foi pela franqueza, pela lealdade com que falou àquêle Príncipe estouvado, mal educado, e que "jamais viveu com pessoas instruídas". E' mesmo extraordinário que um mês apenas depois de se conhecerem D. Pedro assim se dirigisse ao seu ministro:

"Recebi a sua carta e nela judiciosas reflexões, as quais eu aprovo muito e agradeço; e digo que se todos 
os príncipes que quisessem obrar precipitadamente (assim como pelo Diabo eu ia fazendo) tivessem um amigo como eu me prezo de ter, êles nunca se deslustrariam e a sua glória seria multiplicada todos os dias..."

seria inábil o ministro conhecido como multiplicador da glória do príncipe?

Mas, além de se tornar o conselheiro, também se fizera o amigo no qual D. Pedro encontraria confôrto e compreensão. Permiti que vos leia esta carta, tão cheia de humanidade, e que traz a data de 3 de fevereiro de 1822:

"José Bonifácio. Chorando escrevo esta a dizer-Ihe que venha amanhã aqui ao despacho às horas do costume, porque lá não posso ir visto o meu Querido filho estar exalando o último surpiro, e assim não durará uma hora. Nunca tive, e Deus permita que não tenha outra ocasião igual a esta como foi dar-lhe o último beijo, e deitar-lhe a derradeira bênção Paterna. Calcule pelo amor que tem à sua família e ao meu filho qual será a dôr que transpassa o coração Dêste seu amo e amigo Pedro"

E podeis estar certo de não haver sido êste nem um dos menores, nem dos mais fáceis serviços do Patriarca à causa da Independência. Já no exílio, êle díria com o coração aberto: "Sem a monarquia não haveria um centro de fôrça e união, e sem esta não se poderia resistir às Côrtes de Portugal e adquirir a Independência Nacional." Mas, o que nos assegura a veracidade dêsses sentimentos de José Bonifácio não são estas palavras, que poderíamos julgar suspeitas, mas o que nos informa a respeito Maria Graham, que é expressa quanto ao propósito da conquista de D. Pedro para a nossa causa. "Os Andradas, escreveu a memorialista inglêsa, compreendendo que o Brasil não poderia continuar sob o domínio de Portugal por mais tempo de maneira nenhuma, mas desejosos de poupar a efusão de sangue... cultivaram ardorosamente a ambição do Príncipe de tornar-se o líder da grande revolução que se processava."

De fato, o que distingue, o que separa, o que distancia José Bonifácio dos seus opositores - e êsse é o seu grande título - não é a Independência. Esta, quando foi feita, ou pelo menos na proximidade de ser realizada, todos os brasileiros a queriam. Mas, como fazê-la? Não deve ser esquecido no entanto, e a propósito convém invocar o testemunho de Heitor Lira, sempre tão infenso ao Patriarca, que a pala- 
vra revolução, muito usada na época, não era sinônima de Independência, e sim de um movimento republicano, também chamado anárquico. Mareschal, freqüentemente, denomina de anárquico o partido de Ledo. Do mesmo modo que ao reconhecer como pequena a facção republicana dos partidários da Independência, enquanto aqui estivesse D. Pedro, acrescentava: "se pelo contrário êle deixar o país, todos os brasileiros se unirão aos republicanos." E quem duvidará que a República seria o esfacelamento?

O que marca, na realidade, a posição de José Bonifácio na campanha da Independência é que êle a quis acima de tudo sem prejuízo da unidade nacional. E esta - com a larga visão dos estadistas - êle compreendera ser difìcilmente alcançada sem a monarquia, ou mais precisamente sem a figura de $\mathrm{D}$. Pedro. Tinha razão para tanto, pois se bem próximo havia o exemplo de tôda a América Espanhola, tôda ela mergulhada em terríveis lutas divisionistas, mesmo no caso do Prata, que ostentava em favor da unidade o estuário do imenso rio, que não seria o Brasil, todo êle uma fachada voltada para o Atlântico? Mas, não era só. Se, internamente, a monarquia, com a figura um tanto romântica e cavalheiresca de D. Pedro, representava um ponto de aglutinação, externamente serviria para tranquilizar, para apaziguar essa imensa e organizada fôrça internacional que foi a Santa Aliança, sempre assustada com o espectro republicano, que se dispunha ou pelo menos desejava combater e esmagar onde aparecesse.

Daí o empênho demonstrado por José Bonifácio em adormecer as Potências européias lideradas por Metternich. Nisso, aliás, nesse jôgo de tranquilizá-las, se não as iludiu, foi perfeita a ação do ministro dos Estrangeiros, ao qual cabia, através de um jôgo dúplice, ou pelo menos de meias verdades, assegurar que tudo era feito para evitar mal maior. Bem ajudado pelo príncipe, cuja dubiedade de linguagem está sublinhada num ofício de março de 1822 a Metternich. Assim, a propósito da convocação da Assembléia Geral das Províncias, idéias que não podia ser do agrado de um absolutista como Mareschal, José Bonifácio, apontado como inspirador da idéia, dissera-lhe com ar cético: "que quereis, se todos os espiritos estão voltados para lá, e não se pode resistir à corrente? estamos em estado de febre; e o Príncipe sòmente a convocará se tôdas as Províncias estiverem de acôrdo." Maneira de colocar uma dose de dúvida no espírito do interlocutor, que, afinal, sentia-se tranquilo ou conformado. Por sinal, conta Sa- 
pucaí que, informado sôbre a idéia da Constituinte, respondera o ministro: "Façam o que quiserem, na inteligência de que nem convém apressar, nem impedir a Constituinte." Ela viria a seu tempo, como pedra dêsse jôgo de enganos e equívocos propositados, que fazem com que, ao consumar-se a convocação, ela, por suave ironia, apareça para mantença da integridade da monarquia portuguêsa." Não dizia Talleyrand que as palavras eram para esconder o pensamento?

Mais eloqüente, entretanto, é a posição de José Bonifácio por ocasião do manifesto de 6 de agôsto, natural desdobramento do decreto de $1 .^{\circ}$ de agôsto, no qual, verdadeiramente, D. Pedro não deixava mais dúvida quanto à marcha acelarada para a Independência, e no qual, com as próprias mãos, e atendendo ao "unânime consentimento dos povos do Brasil", tomava o título de Regente. Numa linguagem desabrida, inteiramente fora de moldes diplomáticos, o ministro punha na bôca do príncipe os mais rudes ataques a Portugal e aos portuguêses. Terrível libelo, que êle enviou ao corpo diplomático declarando que o Brasil, havendo "sacudido o jugo da sujeição e inferioridade", passara a "proclamar solenemente a sua independência".

Frases que deviam gelar o representante de Metternich. Contudo, José Bonifácio conseguira convencê-lo - e isso é admirável como capacidade de persuasão - que não havia porque se assustar. E Mareschal assim escreve para a sua Côrte: "malgrado as frases freqüentes, e que acredito desnecessárias, sôbre liberalidade, soberania do povo, direitos imprescritíveis das nações que parecem renovar todos êsses direitos, o Sr. Andrada não é nem um democrata, nem um liberal na acepção comum do têrmo; êle luta contra a revolução, não acalmando e esclarecendo os espíritos, mas desviando-os e apresentando-lhes outro objetivo, mais imediato e mais identificado com os seus interêsses... A fim de fazer Americanos em vez de revolucionários." Vemos aí, nitidamente, José Bonifácio apresentando-se em "luta contra a revolução", isto é contra a república e a anarquia, ao mesmo tempo em que justifica aquêle "proclamar solenemente a sua independência" pela necessidade de "fazer Americanos em vez de revolucionários". Salta aos olhos. Como sempre, e à medida que avançava,; José Bonifácio precisatva amansar a Santa Aliança., Também por ocasião da Aclamação, que segundo uma carta de Gameiro Pessoa a José Bonifácio, depois de haver encontrado Metternich em Verona, fôra por êste recebida com estu- 
pefação, também nessa ocasião tratou o ministro do Reino de pôr um pouco de mel nos lábios do ministro austríaco. E explicou: caso não se procedesse logo à Aclamação esta se verificaria perante a Constituinte e D. Pedro, em vez de proclamado diretamente pelo povo, ficaria numa "dependência extrema e muito perigosa diante dessa assembléia". Não seria exato? Dona Leopoldina também dissera o mesmo. $\mathrm{E}$ assim, de etapa em etapa, sem suscitar desconfianças. internacionais maiores, José Bonifácio fazia a independência. E de tal modo que ao pleitear o reconhecimento da Independência, não se esquivou sequer de afirmar ao delegado do sôgro do Imperador que, em breve, contaminada pelo bom exemplo, tôda a América do Sul seria monárquica. Bolivar estaria prestes a proclamar-se Imperador; o Chile tinha igual tendência; e Buenos Aires, premida entre êsse país e o Brasil, seguiria a mesma trilha. E como tudo era propositadamente bem dourado, até o título de Imperador era apresentado como o de governante de um grande Império, em substituição ao de Rei, que se poderia chocar com o de D. João VI. Por que, então, não reconhecerem logo as grandes monarquias européias aquêle frutuoso exemplo americano? Não há dúvida de que o homem tido como mau político, impulsivo, e de cabeça quente, dá belo exemplo de que muitas vêzes a inteligência - e êle a tinha poderosa - consegue sobrepor-se ao temperamento. Com firme determinação, comandando os acontecimentos, José Bonifácio atingiu de modo particularmente feliz o seu propósito de neutralizar as naturais desconfianças monárquicas em face do movimento emancipador brasileiro, que privava da corôa o rei D. João VI.

Mas, se na ordem internacional tôda a ação de José Bonifácio se desenvolveu calculadamente no sentido de evitar maiores dificuldades, dificuldades que poderiam ser invencíveis e, portanto, fatais à unidade brasileira, no plano interno todo o seu esfôrço se concentra no propósito de fortalecer o príncipe. Começara por conseguir a permanência de $\mathrm{D}$. Pedro, resultando daí o ódio que lhe votavam os portuguêses, seguros de haver sido êle o artífice do Fico. Em seguida, especialmente por ocasião da viagem de $\mathrm{D}$. Pedro a Minas Gerais, coube-lhe ser o indormido guardião da ordem. Como pensar-se na luta da Independência, na guerra contra Portugal, se a frente interna estivesse abalada por grave dissenção?

Contudo, em boa hora o súdito e o príncipe estavam não apenas entendidos, mas vinculados por confiança recíproca. 
São do mesmo dia 6 de abril de 1822 estas duas cartas, uma de José Bonifácio dirigida a $\mathrm{D}$. Pedro, outra dêste, que se encontrava em São João D'El Rei, para o seu ministro. E servem, acredito, para propiciar uma idéia sôbre os homens e os fatos. Informava o ministro:

\begin{abstract}
"Senhor. Como desde 28 de março não tenho recebido de V. A. carta ou notícia certa da sua preciosa saúde, e do andamento político da sua importantíssima viagem, meu coração tem andado inquieto... E' do meu dever, aproveitando a ocasião, dar parte a V. A. R. que aqui tudo está por ora tranquilo, porém para o dia 18 , da eleição dos Procuradores Gerais, teme alguma gente medrosa uma nova bernarda, ou para mudar de Ministros, ou para obstar a eleição. Segundo as minhas pesquisas parece que tem havido clubes secretos para êste fim; há suspeita que entram nêles os Desembargadores José Albano, Antônio Luís, Luís de Oliveira, o Juiz do Crime do Bairro de Santa Rita, o Garcez, e até dizem, o que me é difícil crer, que entra o Tinoco e mais alguns oficiais militares Europeus. Eu não durmo, e vigio sôbre tais energúmenos... Contra mim puseram dois pasquins esta semana: um dizia - Agora governa o Pachá, daqui a duas semanas onde estará? e o outro: Agora impera o Pachá paulista. daqui a dias mandará outro $\mathrm{Fu}$ lano; êste apareceu na Mãe dos Homens. Eu que nada temo, ainda costumo rondar a pé a cidade, porém, com mais cuidado para não dar caneladas".
\end{abstract}

Vejamos agora o que dizia o príncipe:

"Meu José e amigo. Recebi sua carta de 31 do p. p., e estimo que tudo esteja sossegado; faz bem praticar o que tem praticado relativo aos faladores, e digo mais se fôr Criado meu nenhuma compaixão com êle. Levo o Capitão comigo mas debaixo de olho. Mande já e já de ordem minha chamar o Governador que foi de São Paulo, e assim ficaremos em paz, e é tempo de se mostrar o dedo do Gigante. Não terei compaixão com nenhum e não farei despotismo porque os aborreço muito".

Sinal de que amo e ministro estavam acordes. Mas, a julgar por uma carta do ministro a D. Pedro, em 23 de abril, fôra grande o perigo atravessado pela ordem pública.

"Nós desgraçadamente - escreveu José Bonifácio - temos dormido à borda de um precipício, e desgraçadamente os que deviam vigiar noite e dia sôbre a segurança interna, parte por indolência, e parte por egoismo, ou talvez por traição tem abandonado a nau do Es- 
tado sem leme e sem velas ao impeto dos ventos e borrascas. Ah! se não fôra a Providência, nem V. A. Imperial, nem eu teríamos salvado o Brasil!"

Convém notar, portanto, que num momento de grave apreensão, e quando enfrentava fortes adversários, não falava o ministro na salvação dêle, ou de $\mathrm{D}$. Pedro, mas na salvação do Brasil, que, afinal, era o que realmente devia importar ao homem público. Até porque essa capacidade de sobrepor os interêsses coletivos às próprias conveniências é que nos dá a medida do estadista.

Disse-vos há pouco, repetindo Barthou, ser a ação a pedra de toque do verdadeiro político. Pois bem, o nosso grande Andrada não teme a prova. "Sabendo o que queria", conforme a segura observação de Otávio Tarquínio de Souza, na sua monumental História dos Fundadores ldo Império, logo se dispôs José Bonifácio, ante os acontecimentos iminentes, a "orientar êsses sucessos e não ser por êles impelido". Por isso, mal assume o govêrno, e dentro daquele objetivo de preservar a unidade nacional, êle logo pratica três atos que são o testemunho da segurança do timoneiro. Não vacila. Inicialmente determina que as leis vindas de Portugal sòmente sejam remetidas às repartições, e, portanto, produzam efeitos depois do Príncipe determinar a sua execução. Decisão que tinha como conseqüência imediata o reconhecimento da autoridade de D. Pedro em todo o território nacional. Por outro ato os governos provisórios de tôdas as províncias deviam unir-se sob a regência do filho de D. João VI. Finalmente, a 16 de fevereiro, como sabeis, fêz-se a convocação da "Junta de Procuradores", que congregaria as províncias "em um centro comum de união e de interêsse recíprocos".

Se insisto nesses aspectos da atividade do eminente ministro, é por nos mostrarem, de modo ineqüívoco, que para fazer a independência sem prejuízo da unidade nacional, a sua ação deligente e lúcida é monolítica. Não há brechas, não há falhas, não há pontos fracos. Tudo é preciso, pronto, e seguro. Que importa que o acoimem de arbitrário, apaixonado, inflexível com os inimigos, se tôda a sua ação se desenvolve no sentido de assegurar, como de fato assegurou, a existência da pátria nas dimensões que acredito bem menores sem a sua presença? Que importa se êle será sempre, para usarmos de uma expressão de Armitage, o "primeiro motor de todo êste procedimento"? E quem nos dirá que, a exemplo do Cardeal 
Richelieu, não poderia redarguir aos seus detratores que os seus inimigos eram apenas os da pátria?

Euclides da Cunha, com o vigor que lhe é peculiar, ao estudar a ação de José Bonifácio, justamente na hora em que precisou ser mais enérgica, - e isso sem prejuízo da sua admiração pelo grupo da maçonaria - assim se externa sôbre o movimento libertador:

"Era forçoso reguiá-lo, contendo-o e retificando-o. Foi a notável tarefa de José Bonifácio, cujo ministério salvou a revolução com uma política terrivel de Saturno: esmagando os revolucionários. Sombream-no, com efeito, à luz de um critério superficial, medidas odiosas: destruiu a liberdade de imprensa, suprimindo os próprios jornais que o aplaudiam na véspera; e, com rigor excessivo, arredou de cena ruidosa, em que eram protagonistas, Clemente Pereira, Gonçalves Ledo e Januário da Cunha Barbosa, desterrando-os para o Rio da Prata e para a França. Esta reação contra os três maiores agitadores da Independência é expressiva".

E; pondo de lado o critério superficial, certo de que para julgar o Patriarca precisamos pesar o sentido histórico da sua obra, o autor d'Os Sertões assim arremata o seu pensamento:

"Vê-se que o grande homem vingara, num lance genial, o fastígio de uma crise. Iniciava a função reconstrutora urgente, sôbre o terreno móvel das paixões".

A sentença é admirável pela exatidão histórica. De fato, no curso das várias batalhas políticas que travou entre 1821 e 1826, José Bonifácio precisou discordar, lutar, reprimir, e algumas vêzes punir. Mas, se lhe analisarmos os atos, mesmo aquêles apontados como violentos ou arbitrários, veremos que jamais se inspiraram em razões mesquinhas, de ordem pessoal, se não nos mais altos interêsses da nacionalidade.

Ou poderemos esquecer que, na ocasião mesma da Independência, ainda estávamos a braços com as mais graves ameaças à unidade do Brasil? A Bahia, dominada pelo general Madeira, perigava nos canaviais do Recôncavo; Pernambuco, ainda aquecido pelo espírito revolucionário, era uma interrogação nas suas relações com D. Pedro; o Maranhão continuava profundamente ligado à metrópole portuguêsa; o Piauí, sob o jugo do major Fidié, permanecia fora da órbita do Rio de Janeiro; e o mesmo acontecia, no extremo norte, com o Pará. Seria tranqüilizador êsse quadro? Poderia o Brasil dar-se ao luxo das pequenas querelas, que ameaçavam agitar, dividir, e enfraquecer o govêrno então representado por José Bonifácio? 
E' à luz dessas perguntas e daquele panorama que êle deverá ser julgado. $\mathrm{E}$ também do grande, do benemérito, do patriótico objetivo de alcançar a independência dentro da unidade. De uma unidade que o leva, com a ampla visão do verdadeiro homem de Estado, a cuidar logo da organização da nossa Marinha de Guerra, para a qual iria buscar a experiência e a bravura do almirante Cochrane. Da unidade em cujo nome traz para a nossa guerra a figura heróica de Labatut. Não proclama Tobias Monteiro que o problema máximo de congraçar as províncias em tôrno do poder central continuava de pé?

Pois bem, é ainda para salvar essa unidade, hoje o nosso orgulho e a nossa fôrça, que José Bonifácio põe um ligeiro compasso de espera na convocação da Constituinte, a fim de que ela seja efetivada, não pela exigência de um grupo, mas pela determinação acorde de $\mathrm{D}$. Pedro e do Conselho dos Procuradores das próprias províncias. $\mathrm{E}$ por que não lembrarmos o episódio do chamado "juramento prévio"?

Como é sabido, ao tratar da Aclamação, a ser realizada no dia 12 de outubro, conviera o grupo da maçonaria em que o príncipe, na ocasião, também juraria "guardar, manter, e defender", a Constituição a ser elaborada pela Constituinte. José Bonifácio embargou-lhes o passo. Por que? Capricho? Ciúmes, por não haver tido a iniciativa? Nada disso. Do mesmo modo que se batera e justificara a Aclamação antes da Constituinte a fim de poupar Sua Alteza a "uma dependência extrema e muito perigosa em fase dessa assembléia", e contrária à política do fortalecimento de $\mathrm{D}$. Pedro, do mesmo modo, e com idêntica finalidade, êle considerou pernicioso o juramento prévio, o juramento às cegas, como em tão má hora fizera D. João VI, o juramento no escuro. Que faria aquela assembléia, cuja orientação e critério José Bonifácio era o primeiro a pôr em dúvida?

O que desêjo ressaltar é que êsse pensamento do fortalecimento do príncipe é uma constante na ação política de José Bonifácio. Nunca mudou. $E$ isso porque obedecia não a uma conveniência pessoal - e sabemos quanto as conveniências são mutáveis na vida pública - mas a um pensamento superior, que era o de fazer de $\mathrm{D}$. Pedro, naquela fase difícil, o polo, o ímã, para o qual fôsse atraída tôda a nacionalidade. Atitude com a qual evitou, sem dúvida, que ocorresse aquilo que Saint Hilaire temera quando nos aconselhou a que nos acautelássemos 


\begin{abstract}
"contra a anarquia de uma multidão de tiranetes mil vêzes insuportáveis do que um déspota único".
\end{abstract}

E José Bonifácio estava tão consciente, tão lúcido, em relação a êsse problema que escreve, em outubro, a Barbacena sôbre a aclamação:

\begin{abstract}
"é impossivel que S. A. R. deixe de anuir quanto antes ao único meio de centralizar para sempre em si a Revolução Brasílica e dirigíla a bem dos povos".
\end{abstract}

Tanto José Bonifácio se identificara com a questão da unidade nacional que a Representação popular de 30 de outubro, solicitando a $\mathrm{D}$. Pedro a volta do ministro ao poder, explica e afirma ser êle visto "como o terror dos tenebrosos e incendiários partidos", que levariam à "desunião das suas mais belas Províncias, das quais em umas reinará a Aristocracia, em outras a Democracia, e em tôdas a confusão, o despotismo, a desolação, e a guerra civil." Mas, para êle, sòmente um príncipe fortalecido poderia afastar tão negras nuvens. Por isso, no momento mesmo em que, ao lado de D. Pedro, na sacada da casa do Largo do Rocio, acede em tornar ao govêrno, a primeira coisa que faz - réplica aos artigos do Correio do Rio de Janeiro, que falara em Pedro I, sem II - é dar ostensivo viva a Pedro I, Pedro II, Pedro III, e Pedro IV. Que fôrça maior do que essa de transmitir ao herdeiro o poder e as honras da realeza?

Sempre preocupado com a autoridade do nôvo Regente, José Bonifácio, quando aquêle, na coroação, profere a rumorosa frase ambígua, jurando defender a Constituição "se fôr digna do Brasil e de mim", José Bonifácio logo surge para indagar: "como é possível que do mel puro do discurso de Sua Majestade Imperial distilem veneno?" E outro Andrada, Antônio Carlos, advertira a inquieta assembléia de que havendo a nação eleito um imperador constitucional, dando-lhe o poder executivo, "nisto não podemos nós bulir". Na realidade era inevitável e fatal a'luta entre os dois poderes.

Também não demorará muito a queda dos Andradas, que se disse batidos pela poderosa Marquesa de Santos.

$$
\begin{aligned}
& \text { "Vencera a conspiração dos mediocres contra o ho- } \\
& \text { mem superior". }
\end{aligned}
$$

Mas, se até aqui, se até o momento em que deixa o govêrno, em julho, poderíeis dizer que as suas relações e o seu esfôrço em favor da crescente autoridade de D. Pedro decorriam também 
do empênho do ministro, do áulico diante do amo e Senhor, já agora nada disso ocorre. Entretanto, quando apreende com aquela admirável inteligência, que lhe permitia ver mais longe, quanto será difícil chegar a Constituinte a bom têrmo, é êle quem toma a iniciativa de mandar sugerir a $D$. Pedro que envie mensagem à assembléia solicitando, face aos perigos iminentes - entre os quais mencionou a situação de Pernambuco, de fato convulsionado dentro em pouco pela revolução de 1824 - a imediata aprovação, por aclamação da carta constitucional. Colocava-se assim acima do despeito, ou dos ressentimentos. Certa, democrática, possível aquela sugestão?

Hoje o que nos importa é a altitude do patriota e do estadista, capaz de se despojar de interêsses, afrontar preconceitos, para seguir o que lhe parecia a salvação do Brasil.

Para um esbôço da extraordinária e incomparável figura de José Bonifácio, Patriarca da nossa Independência, ja vos disse talvez o bastante, dentro das minhas limitações. Quero, porém, invocar ainda esta síntese magnífica de Otávio Tarquínio de Souza, nome que não podemos pronunciar sem vivo aprêço e comovida saudade:

"Sem êle no govêrno, escreve o severo historiador, e sem a presença de D. Pedro, a unidade do vasto Império teria sido preservada com dificuldades muito maiores, e o Brasil, dividido e dilacerado, não escaparia provàvelmente aos transes do caudilhismo e da tirania militar".

Quanto a mim, confesso que vou mais longe, pois não acredito que sem a feliz associação das duas fortes personalidades, do príncipe e do Patriarca, houvesse sido preservada a unidade nacional contra a qual, ao contrário do que é freqüente se dizer, conspiravam poderosos fatôres, e dos quais não seria dos menores uma costa de milhares de quilômetros. Ele, entretanto, venceu todos êsses elementos adversos. Fê-lo, não pelo acaso, mas pela inteligência, pela capacidade de prever e prevenir, pelo trabalho e pela paixão com que se dedicou a esta obra, a maior de tôdas da nossa História, e que foi a de conservar unido o imenso território, cuja grandeza se reflete nas vinte e quatro estrêlas da nossa bandeira, cada uma delas a iluminar para sempre a glória de José Bonifácio.

Não vos falarei do exílio, do sofrimento, e também das grandezas que ainda passaram por essa vida extraordinária. Pedirei, porém, licença para ler esta carta que do exílio, escreveu em 23 de outubro de 1824, ao Visconde da Pedra Branca: 
"Não respondi logo a amigável carta de V. S. de 25 de setembro passado porque as minhas moléstias não me deixavam... agora, porém, que posso vou cordialmente agradecer-lhe o prazer que mostrou com a minha eleição para senador pela cidade da Bahia; e também iguais parabéns lhe dou pela sua. Ainda que conheço bem à minha custa o que devo esperar de gratidão dos homens em geral, e mormente dos da raça portuguêsa daquem e dalem mar, todavia não deixou de ser-me agradável a lembrança dêsses setenta e tantos Baianos: pois vejo que ao menos na sua Província houve quem não se quis esquecer dos meus contínuos esforços para que se mandassem socorros repetidos àquela Província contra os vândalos de Portugal...

A unidade dourava-lhe as últimas ilusões.

Hoje, volvido quase século e meio, e quando se celebra o segundo centenário do seu nascimento na gloriosa cidade de Santos, aqui estamos. Aqui estamos, para dizer a José Bonifácia de Andrada e Silva que, à sombra da grande árvore da nacionalidade que êle preservou, aquêles setenta e tantos Baianos são hoje alguns milhões, todos êles fiéis e agradecidos ao excelso Patriarca da Independência.

LUIZ VIANNA FILHO

Deputado Federal por São Paulo. 